\title{
Search for Novel Mutational Targets in Human Endocrine Diseases
}

\author{
So Young Park ${ }^{1}$, Myeong Han $\mathrm{Seo}^{2}$, Sihoon Lee ${ }^{2}$ \\ ${ }^{1}$ Department of Internal Medicine, Cheil General Hospital \& Women's Healthcare Center, Seoul; ${ }^{2}$ Department of Internal \\ Medicine and Laboratory of Genomics and Translational Medicine, Gachon University College of Medicine, Incheon, Korea
}

The identification of disease-causing genetic variations is an important goal in the field of genetics. Advancements in genetic technology have changed scientific knowledge and made it possible to determine the basic mechanism and pathogenesis of human disorders rapidly. Many endocrine disorders are caused by genetic variations of a single gene or by mixed genetic factors. Various genetic testing methods are currently available, enabling a more precise diagnosis of many endocrine disorders and facilitating the development of a concrete therapeutic plan. In this review article, we discuss genetic testing technologies for genetic endocrine disorders, with relevant examples. We additionally describe our research on implementing genetic analysis strategies to identify novel causal mutations in hypocalcemia-related disorders.

Keywords: Genes; Mutation; Endocrinology; Genomics; High-throughput nucleotide sequencing

\section{INTRODUCTION}

Numerous diseases are caused or influenced by genetics. Significant advances in genetic technology have extended our knowledge of the genetic abnormalities related to endocrine disorders and furthered our understanding of the etiology of many endocrine diseases.

Genetic diseases can be categorized into three major groups: single-gene, chromosomal, and multifactorial [1]. Changes in the DNA sequence of single genes involve alterations of single bases in the DNA or the deletion or gain of a single base or multiple bases. Single-gene mutations generate altered protein products that usually have reduced or totally disabled functionality. However, in some cases, the altered protein produced by a genetic mutation may gain a new function. Chromosomal abnormalities result from changes in the total number or structure of chromo-

Received: 22 December 2018, Revised: 23 January 2019,

Accepted: 7 February 2019

Corresponding author: Sihoon Lee

Department of Internal Medicine, Gachon University College of Medicine, 38 Dokjeom-ro 3beon-gil, Namdong-gu, Incheon 21565, Korea

Tel: +82-32-458-2662, Fax: +82-32-460-2381, E-mail: shleemd@gachon.ac.kr somes. Multifactorial diseases are caused by a complex combination of genetic, behavioral, and environmental factors [1].

Mutational analyses are performed for many different purposes, such as confirmation of molecular diagnoses, identification of asymptomatic family members carrying the mutation, prenatal testing, and facilitating earlier treatment [2]. Today, various genetic tests are available, including cytogenetic tests, singlegene tests, gene panels, and exome/genome sequencing [3]. Recent technical developments have enabled the rapid identification of relevant genes with phenotype-causing mutations, extensive analyses of entire genomes of multiple individuals or populations, as well as a progressive diminution of costs and time.

The aim of this review is to present an overview of advances in genetic technology and to provide a general description of genetic approaches to endocrine disorders. This review also describes applications of clinical genetic testing within the field of

Copyright $\odot 2019$ Korean Endocrine Society

This is an Open Access article distributed under the terms of the Creative Commons Attribution Non-Commercial License (http://creativecommons.org/ licenses/by-nc/4.0/) which permits unrestricted non-commercial use, distribution, and reproduction in any medium, provided the original work is properly cited. 
endocrinology, especially for hypocalcemia-related disorders.

\section{CURRENT TECHNOLOGY IN GENETIC TESTING}

A key goal in the field of clinical genetics is the identification of genetic variations responsible for disease-related phenotypes.

As the first step in the genetic approach, a careful family history plays an important role in determining whether a disorder in a presenting patient is likely to be genetic [4]. A family history helps to determine the mode of inheritance and variable manifestations of the disease in the family. It is critical to investigate whether family members were affected for at least three generations. Ethnicity is important, as each ethnic group has a specific preponderance of certain genetic disorders [5].

Diagnoses of chromosomal disorders were traditionally based on cytogenetic tests, which involve the examination of whole chromosomes for abnormalities using karyograms and fluorescence in situ hybridization (FISH) in a cell-by-cell manner [1,6].

Microarray-based techniques began to replace cytogenetic testing starting in 2005 [7]. Array-based comparative genomic hybridization $(\mathrm{aCGH})$, which was first introduced as a microarraybased test, facilitates the detection of genomic copy number variations (CNVs) at a much higher resolution than was possible using traditional methods [6]. Genome-wide single-nucleotide polymorphism (SNP) arrays released after the development of aCGH were technically able to analyze both SNPs and CNVs [8].

Mendelian disorders, which are also known as monogenic disorders, are caused by a mutation in a single gene and inherited in an autosomal dominant, autosomal recessive, or X-linked pattern [9]. A gene is a sequence of DNA located on a chromosome, and the human genome contains more than 20,000 genes. The sequence of nucleotides in a gene is translated into amino acids [6]. Molecular testing is based on nucleotide variation and typically involves gene sequencing. Single-gene sequencing is accomplished by analyzing DNA extracted from a small blood sample, cultured or non-cultured amniotic fluid cells, chorionic villi, or from any tissue [5].

In 1977, Sanger et al. [10] published a new method of DNA sequencing. Sanger's chain termination technique, known as Sanger sequencing, is a mixed-mode process involving the synthesis of a complementary DNA template using natural 2'-deoxynucleotides (dNTPs) and termination of synthesis using 2',3'-dideoxynucleotides (ddNTPs) by DNA polymerase [10, 11]. The competition between synthesis and termination processes results in the generation of a set of nested fragments. The nested fragments are then separated by size using high-resolution gel electrophoresis and analyzed to reveal the DNA sequence [11]. Automated Sanger sequencing is a fluorescencebased approach that uses either the primer or the terminating ddNTP tagged with a specific fluorescent dye and analyzes the different colors of fluorescence signals [11].

Concurrent with the evolution of large-scale dideoxy-based sequencing, a newly developed non-Sanger method was emerged. This method, first described by Hyman [12], is pyrosequencing, which is a non-fluorescence technique that measures the release of inorganic pyrophosphate during enzymatic reactions via a luminescent method $[13,14]$.

A growing demand for increased throughput and rapid progress in technology led to the development and commercialization of next-generation sequencing (NGS) technologies, as opposed to the Sanger method. NGS is a high-throughput technique that enables the mass parallelization of sequencing reactions. The NGS technology has several distinctive points compared to the previous Sanger method. First, instead of requiring bacterial cloning of DNA fragments, NGS relies on the preparation of NGS libraries in a cell-free system. Second, numerous sequencing reactions can be performed in parallel. Third, the sequencing output is directly detected without the need for electrophoresis, and results can be obtained in real time [15]. As NGS platforms have become widely available, it has become easier to determine coding variations at a lower cost and to identify disease-related variants when conventional approaches have failed [9]. The diagnostic rates of NGS are variable; selected genes panels sequenced by a NGS method showed a diagnostic rate of approximately $30 \%$ and $50 \%$ in early-onset epilepsy and inherited retinal diseases, respectively [16].

In comparison with customized and targeted gene panel testing (targeted NGS), there are two unbiased sequencing approaches for detecting genetic variations within an individual: whole genome sequencing (WGS) and whole exome sequencing (WES) (Table 1). The WGS approach can detect all genomic variation in both the $1 \%$ coding region and the remaining noncoding regions that comprise $99 \%$ of a patient's genome. However, the use of this approach is limited to gene discovery research at a few large centers due to limitations of the current technology and its high cost. WES is focused on capturing phenotype-altering mutations in the exome (i.e., the protein-coding region) and other functional elements, such as microRNA sequences $[17,18]$. Though the actual diagnostic rate with WES is highly dependent on the tested population and characteristics of diseases, diagnostic rates have reached up to $60 \%$ in selected 


\begin{tabular}{|c|c|c|c|c|}
\hline & \multirow{2}{*}{ Sanger sequencing } & \multicolumn{3}{|c|}{ NGS } \\
\hline & & Targeted NGS & WES & WGS \\
\hline Expected detection range & $\begin{array}{l}\text { Small to medium indels } \\
(<300 \mathrm{bp}) \\
\text { Introns } \\
\text { Promoters }\end{array}$ & $\begin{array}{l}\text { Small to medium indels } \\
(<300 \mathrm{bp}) \\
\text { Introns } \\
\text { Promoters }\end{array}$ & $\begin{array}{l}\text { Small to medium indels } \\
(<300 \mathrm{bp}) \\
\text { Introns } \\
\text { Promoters }\end{array}$ & $\begin{array}{l}\text { Small to large indels } \\
\text { Introns } \\
\text { Promoters }\end{array}$ \\
\hline Candidates for application & $\begin{array}{l}\text { Detection of known muta- } \\
\text { tions and research into new } \\
\text { causative genes }\end{array}$ & $\begin{array}{l}\text { Analysis of known causative } \\
\text { genes }\end{array}$ & $\begin{array}{l}\text { Identification of new } \\
\text { causative genes }\end{array}$ & $\begin{array}{l}\text { Studies of population } \\
\text { genomics }\end{array}$ \\
\hline Advantages & $\begin{array}{l}\text { Traditional and practiced } \\
\text { methodology } \\
\text { Cost-effective analysis for } \\
\text { targeted mutations } \\
\text { Ability to detect mutations } \\
\text { in pseudogenes and GC- } \\
\text { rich genes }\end{array}$ & $\begin{array}{l}\text { Proper option in clinical } \\
\text { application } \\
\text { Customizable for different } \\
\text { sample types } \\
\text { Relatively low cost }\end{array}$ & $\begin{array}{l}\text { Identification of SNVs, } \\
\text { indels, SVs, and CNVs in } \\
\text { coding regions } \\
\text { Detection of mutations in } \\
\text { unsuspected genes } \\
\text { Moderate cost between } \\
\text { targeted NGS and WGS }\end{array}$ & $\begin{array}{l}\text { Identification of SNVs, } \\
\text { indels, SVs, and CNVs in } \\
\text { coding and non-coding } \\
\text { regions } \\
\text { PCR not required } \\
\text { Obtaining complete genetic } \\
\text { information }\end{array}$ \\
\hline Limitations & $\begin{array}{l}\text { Variable costs depending on } \\
\text { gene size and exon number } \\
\text { False negatives if the wrong } \\
\text { area is analyzed } \\
\text { False positive interpretation } \\
\text { for benign polymorphisms }\end{array}$ & $\begin{array}{l}\text { Restricted analysis range } \\
\text { Biases of library preparation } \\
\text { Heterogeneous coverage } \\
\text { Difficult identification of } \\
\text { CNVs }\end{array}$ & $\begin{array}{l}\text { Heterogeneous coverage } \\
\text { High risk of incidental } \\
\text { genetic findings }\end{array}$ & $\begin{array}{l}\text { High cost } \\
\text { Greater effort in data } \\
\text { interpretation }\end{array}$ \\
\hline
\end{tabular}

NGS, next-generation sequencing; WES, whole exome sequencing; WGS, whole genome sequencing; indels, insertions or deletions; GC, guanine-cytosine; SNV, single nucleotide variant; SV, structural variant; CNV, copy number variant; PCR, polymerase chain reaction.

disease cohorts [16,19].

Thanks to technical advancements and more reasonable costefficiency, exome sequencing has rapidly become one of the main strategies in the field of genetic diagnosis. The key challenge for applying exome sequencing for Mendelian disease gene discovery is the identification of disease-related variants in the background of non-pathogenic polymorphisms and sequencing errors. Strategies for finding causal novel alleles include discrete-filtering steps from multiple unrelated and affected individuals, use of pedigree information, sequencing of parentchild trios, and utilizing an extreme phenotype study design [9]. A general approach for finding novel alleles depends on comparisons with exome sequences and variants obtained from unrelated and affected persons to find novel variants in the same gene shared among affected individuals. This discrete-filtering approach is achieved by filtering variants against a set of polymorphisms that are available in public databases and/or those found in a set of unaffected controls. This process plays a key role in condensing a large number of candidate genes into the minimum possible number of high-priority candidates. For identifying likely causal variants of Mendelian diseases, using pedigree information is another valuable approach. Instead of performing exome sequencing on every individual in a pedi- gree, it is more efficient to sequence a pair of affected individuals whose overlapping haplotype is associated with the smallest shared genomic region. Exome sequencing of parent-child trios is an effective method for identifying de novo coding mutations in Mendelian disorders and studying genetically heterogeneous disorders. An extreme phenotype study design involves sampling individuals who are at both ends of a quantitative phenotype distribution for sequencing and comparing the genetic correlates of the phenotypic distribution.

\section{GENETIC TESTING FOR ENDOCRINE DISEASES}

Within the field of endocrinology, some genetic disorders are well known and the causal genetic factors have been identified. However, others are exceedingly rare and their etiology remains almost unknown. As in other medical areas, genetic testing technology has led to significant advances in our understanding of rare genetic syndromes with prominent endocrine involvement, as well as various endocrine disorders, including adrenal disease, growth and pubertal disorders, type 2 diabetes, osteoporosis, and mineral metabolic disorders [20].

Cytogenetic tests such as karyotypes and SNP arrays are ap- 
plied to search for genetic variations at the chromosomal level [4]. The most common cytogenetic test in the endocrine setting is karyotyping to diagnose aneuploid disorders such as Turner syndrome $(45, \mathrm{X})$ and Klinefelter syndrome (45,XXY) [4]. Karyotyping in disorders of sexual development may be complemented by FISH, which employs probes to identify and quantify relevant genes, such as sex determining region Y (SRY) on the $Y$ chromosome. A positive FISH result indicates the presence of the Y chromosome or translocation of the SRY gene onto the $\mathrm{X}$ chromosome, which can be helpful for diagnosing 46,XX complete gonadal dysgenesis [4]. SNP arrays are useful for investigating various endocrine disorders, including PraderWilli syndrome (15q11.2 microdeletion), DiGeorge syndrome (22q11.2 microdeletion) and, more recently, X-linked acrogigantism (XLAG; Xq26.3 microduplication) [4,21].

Molecular tests are suitable for searching for mutations in a single gene or multiple genes. Molecular testing is based on nucleotide variation and typically involves gene sequencing either by Sanger sequencing, which is suitable for targeting an individual gene, or NGS technology. Disorders caused by a few known mutations are good candidates for targeted mutation analysis. Examples include tumor-related syndromes such as multiple endocrine neoplasia type 1 (MEN1), MEN2A, MEN2B, and von Hippel-Lindau syndrome; hormone biosynthetic defect disorders, such as congenital adrenal hyperplasias and glucocorticoid-suppressible hyperaldosteronism (familial hyperaldosteronism type 1); and hormone receptor defects, such as familial hypocalciuric hypercalcemia and thyroid hormone resistance [4].

NGS enables the simultaneous analysis of multiple genes and the choice of targeted NGS, WES, or WGS as a strategy should be determined by the aim, the underlying pathogenesis, and the size of the study. WGS is an appropriate strategy for studies of population genomics. Considering the cost and detection range of gene sequencing, WES is a suitable approach for identifying new genes involved in a particular disease. Among diagnostic genetic techniques, NGS has already increased discovery rate of causative genes clinically and improved diagnosis of rare genetic diseases [16,22]. Targeted NGS is less expensive and more easily manageable than WGS and WES; thus, targeted NGS is being adopted by many genome diagnostic laboratories. Gene panel testing is focused on particular causative genes and is able to reduce the possibility of incidental findings and to obtain results in a relatively short time. With the introduction of NGS, scientific reports using NGS for investigations of endocrine diseases have been dramatically increasing [17]. The NGS ap- proach can be applied to investigate genetic endocrine disorders related to multiple potential genetic causes, such as most endocrine tumor syndromes, disorders of sexual development, congenital hypopituitarism, monogenic diabetes, and hypophosphatemic rickets [4]. Furthermore, NGS can be used to investigate single-gene disorders that eventually prove to have multiple genetic causes. For example, familial Cushing syndrome due to bilateral macronodular adrenal hyperplasia is known to related to armadillo repeat containing 5 (ARMC5), but other causative genes have emerged [4,23]. NGS may be performed in the form of a panel of genes based on a group of disorders, such as metabolic bone diseases. However, a carefully designed and optimized genetic panel immediately becomes outdated following the discovery of a previously unknown causative gene [24].

\section{SEARCH FOR NOVEL CAUSAL MUTATIONS IN HYPOCALCEMIA-RELATED DISORDERS (HYPOPARATHYROIDISM)}

Hypoparathyroidism is a rare endocrine disorder in which parathyroid hormone (PTH) production is abnormally low or absent, resulting in low serum calcium and increased serum phosphorus [25]. In clinical practice, hypoparathyroidism results from anterior neck surgery in approximately $75 \%$ of patients, and it is due to genetic, autoimmune, or idiopathic etiologies in the remainder [26,27]. Inherited causes of hypoparathyroidism may occur as part of syndromic disorders or as a non-syndromic solitary endocrine disease, which is known as isolated or idiopathic hypoparathyroidism [28]. Syndromic forms of hypoparathyroidism involve autoimmune polyglandular syndrome type 1, DiGeorge syndrome type I, CHARGE (coloboma, heart defects, atresia choanae [also known as choanal atresia], growth retardation, genital abnormalities, and ear abnormalities) syndrome, and Kenney-Caffey syndrome [25].

Nonsyndromic forms of hypoparathyroidism (i.e., isolated hypoparathyroidism [IH]) show heterogeneous phenotypes and can be inherited as autosomal dominant, autosomal recessive, and $\mathrm{X}$-linked recessive disorders. The various genetic causes of $\mathrm{IH}$ include defects in glial cells missing 2 (GCM2), which is a parathyroid-specific transcription factor, calcium-sensing receptor (CaSR), the $\alpha$-subunit of the G11 signaling protein (GNA11), PTH, and SOX3 [28].

We have conducted the Korean Hypopara Registry Study since 2010 and recruited 25 patients with sporadic or familial IH [29]. The inclusion criteria were the presence of hypocalcemia, an inappropriately normal or low level of serum intact 
PTH, and normal renal function. Patients with postsurgical hypoparathyroidism or other endocrine disorders were excluded. We conducted a WES analysis in a family diagnosed with autosomal dominant hypoparathyroidism and found approximately 300 single nucleotide changes that were candidates for relevant genetic alterations. After raw data filtering, we selected 22 candidate genes that were possibly related to disease-causing variants. Among them, we identified a novel mutation in exon 2 of $G C M B(\mathrm{C} 106 \mathrm{R})$ in two affected cases and confirmed this variant to be a loss-of-function mutation by direct target gene sequencing and functional studies [26,30]. Additionally, all coding exons and exon-intron borders of GCMB, CASR, and preproPTH were sequenced using polymerase chain reaction-amplified genomic DNA. We revealed disease-related mutations in the CASR gene (D410E and P221L) in other subjects in the Korean Hypopara Registry and verified that CASR D410E was an activating mutation using functional studies [31]. We also published a novel, homozygous arginine-to-cysteine mutation at position 25 (R25C) of the PTH gene in IH patients; this mutation occurs in the mature PTH (1-84) polypeptide and results in reduced bioactivity of the secreted hormone [32]. This unique mutation occurring in the mature PTH-encoding gene causes it to produce a structurally and biologically different PTH molecule. Current ongoing experiments and observations of this mutant form of PTH will enable us to understand its putative ligand-receptor interactions and to seek potential therapeutic applications, especially through a more sophisticated understanding of its mechanism involving a $\mathrm{G}$ protein-coupled receptor and calcium allostery in PTH receptor signaling [33].

Furthermore, WES was helpful in diagnosing brachydactyly type E2 in a patient who was initially misdiagnosed with unclassical pseudopseudohypoparathyroidism [34]. The proband and his mother showed shortening of the fourth and fifth finger and toes with normal serum calcium, phosphorus, and PTH levels. We performed WES of the affected mother and son, using the unaffected father as a negative control, and selected 23 variants with high-priority relevance to the disease. Among the selected variants, we focused on the c.169C $>$ T mutation in parathyroid hormone like hormone (PTHLH), which encodes PTH-related protein, and confirmed this mutation by direct targeted gene sequencing.

\section{CONCLUSIONS}

Today, numerous diagnostic genetic tests enable the identification of new causes of genetic disease and a much broader knowledge of disease mechanisms in the field of endocrinology. As novel genetic techniques have become valuable and revealed unknown mutations, physicians should make the logical decision to be aware of the utility, value, and limitations of the various genetic methodologies.

\section{CONFLICTS OF INTEREST}

No potential conflict of interest relevant to this article was reported.

\section{ORCID}

So Young Park https://orcid.org/0000-0001-6002-0116

Sihoon Lee https://orcid.org/0000-0002-9444-5849

\section{REFERENCES}

1. Terry SF, Chappelle A, Burke BC, Christensen K, Garrison A, Hawkins A, et al. Understanding genetics: a New York, Mid-Atlantic guide for patients and health professionals. Washington, DC: Genetic Alliance; 2010. p. 6-13.

2. Thakker RV, Newey PJ, Walls GV, Bilezikian J, Dralle H, Ebeling PR, et al. Clinical practice guidelines for multiple endocrine neoplasia type 1 (MEN1). J Clin Endocrinol Metab 2012;97:2990-3011.

3. Antonarakis SE, Beckmann JS. Mendelian disorders deserve more attention. Nat Rev Genet 2006;7:277-82.

4. De Sousa SM, Hardy TS, Scott HS, Torpy DJ. Genetic testing in endocrinology. Clin Biochem Rev 2018;39:17-28.

5. Milunsky A. The "New Genetics" in clinical practice: a brief primer. J Am Board Fam Med 2017;30:377-9.

6. Toft M. Advances in genetic diagnosis of neurological disorders. Acta Neurol Scand Suppl 2014;129(S198):20-5.

7. Shah MS, Cinnioglu C, Maisenbacher M, Comstock I, Kort J, Lathi RB. Comparison of cytogenetics and molecular karyotyping for chromosome testing of miscarriage specimens. Fertil Steril 2017;107:1028-33.

8. Biesecker LG, Spinner NB. A genomic view of mosaicism and human disease. Nat Rev Genet 2013;14:307-20.

9. Bamshad MJ, Ng SB, Bigham AW, Tabor HK, Emond MJ, Nickerson DA, et al. Exome sequencing as a tool for Mendelian disease gene discovery. Nat Rev Genet 2011;12:745-55.

10. Sanger F, Nicklen S, Coulson AR. DNA sequencing with chain-terminating inhibitors. Proc Natl Acad Sci U S A 1977; 74:5463-7. 
11. Metzker ML. Emerging technologies in DNA sequencing. Genome Res 2005;15:1767-76.

12. Hyman ED. A new method of sequencing DNA. Anal Biochem 1988;174:423-36.

13. Ronaghi M, Karamohamed S, Pettersson B, Uhlen M, Nyren P. Real-time DNA sequencing using detection of pyrophosphate release. Anal Biochem 1996;242:84-9.

14. Ronaghi M, Uhlen M, Nyren P. A sequencing method based on real-time pyrophosphate. Science 1998;281:363-5.

15. van Dijk EL, Auger H, Jaszczyszyn Y, Thermes C. Ten years of next-generation sequencing technology. Trends Genet 2014;30:418-26.

16. Adams DR, Eng CM. Next-generation sequencing to diagnose suspected genetic disorders. N Engl J Med 2018;379: 1353-62.

17. Persani L, de Filippis T, Colombo C, Gentilini D. Genetics in endocrinology: genetic diagnosis of endocrine diseases by NGS. Novel scenarios and unpredictable results and risks. Eur J Endocrinol 2018;179:R111-23.

18. Gilissen C, Hoischen A, Brunner HG, Veltman JA. Unlocking Mendelian disease using exome sequencing. Genome Biol 2011;12:228.

19. Ghaoui R, Cooper ST, Lek M, Jones K, Corbett A, Reddel $\mathrm{SW}$, et al. Use of whole-exome sequencing for diagnosis of limb-girdle muscular dystrophy: outcomes and lessons learned. JAMA Neurol 2015;72:1424-32.

20. de Bruin C, Dauber A. Insights from exome sequencing for endocrine disorders. Nat Rev Endocrinol 2015;11:455-64.

21. Rostomyan L, Daly AF, Petrossians P, Nachev E, Lila AR, Lecoq AL, et al. Clinical and genetic characterization of pituitary gigantism: an international collaborative study in 208 patients. Endocr Relat Cancer 2015;22:745-57.

22. Wright CF, FitzPatrick DR, Firth HV. Paediatric genomics: diagnosing rare disease in children. Nat Rev Genet 2018;19: 253-68.

23. Gagliardi L, Schreiber AW, Hahn CN, Feng J, Cranston T, Boon $\mathrm{H}$, et al. ARMC5 mutations are common in familial bilateral macronodular adrenal hyperplasia. J Clin Endocrinol Metab 2014;99:E1784-92.

24. De Sousa SM, McCabe MJ, Wu K, Roscioli T, Gayevskiy V, Brook K, et al. Germline variants in familial pituitary tumour syndrome genes are common in young patients and families with additional endocrine tumours. Eur J Endocrinol 2017;176:635-44.

25. Abate EG, Clarke BL. Review of hypoparathyroidism. Front Endocrinol (Lausanne) 2017;7:172.

26. Shoback DM, Bilezikian JP, Costa AG, Dempster D, Dralle H, Khan AA, et al. Presentation of hypoparathyroidism: etiologies and clinical features. J Clin Endocrinol Metab 2016; 101:2300-12.

27. Bilezikian JP, Khan A, Potts JT Jr, Brandi ML, Clarke BL, Shoback D, et al. Hypoparathyroidism in the adult: epidemiology, diagnosis, pathophysiology, target-organ involvement, treatment, and challenges for future research. J Bone Miner Res 2011;26:2317-37.

28. Clarke BL, Brown EM, Collins MT, Juppner H, Lakatos P, Levine MA, et al. Epidemiology and diagnosis of hypoparathyroidism. J Clin Endocrinol Metab 2016;101:2284-99.

29. Park SY, Eom YS, Choi B, Yi HS, Yu SH, Lee K, et al. Genetic and clinical characteristics of Korean patients with isolated hypoparathyroidism: from the Korean Hypopara Registry study. J Korean Med Sci 2013;28:1489-95.

30. Yi HS, Eom YS, Park IeB, Lee S, Hong S, Juppner H, et al. Identification and characterization of C106R, a novel mutation in the DNA-binding domain of GCMB, in a family with autosomal-dominant hypoparathyroidism. Clin Endocrinol (Oxf) 2012;76:625-33.

31. Park SY, Mun HC, Eom YS, Baek HL, Jung TS, Kim CH, et al. Identification and characterization of D410E, a novel mutation in the loop 3 domain of CASR, in autosomal dominant hypocalcemia and a therapeutic approach using a novel calcilytic, AXT914. Clin Endocrinol (Oxf) 2013;78:687-93.

32. Lee S, Mannstadt M, Guo J, Kim SM, Yi HS, Khatri A, et al. A homozygous [Cys25]PTH(1-84) mutation that impairs PTH/PTHrP receptor activation defines a novel form of hypoparathyroidism. J Bone Miner Res 2015;30:1803-13.

33. White AD, Fang F, Jean-Alphonse FG, Clark LJ, An HJ, Liu H. Ca2+ allostery in PTH-receptor signaling. Proc Natl Acad Sci U S A 2019;116:3294-9.

34. Bae J, Choi HS, Park SY, Lee DE, Lee S. Novel mutation in PTHLH related to brachydactyly type E2 initially confused with unclassical pseudopseudohypoparathyroidism. Endocrinol Metab (Seoul) 2018;33:252-9. 